\title{
EJ Moran Campbell - An appreciation
}

\author{
Norman L Jones MD \\ Founding Editor-in-Chief
}

$\mathrm{D}_{\mathrm{s}}^{\mathrm{r}}$ EJ Moran Campbell, Founding Chairman and R Samuel McLaughlin Professor of Medicine at McMaster University, 1968 to 1975, died on April 12, 2004, following a long battle with colon cancer. He was an outstanding scientist, physician and educator, achieving a worldwide reputation as the foremost clinical respiratory physiologist of his generation who changed how respiratory medicine was taught and practiced. He was elected a fellow of the Royal Society of Canada in 1983 and appointed an officer of the Order of Canada in 2001. He suffered intermittently from a mood disorder, which was a great burden. He published an extraordinarily insightful book on his experiences with this debilitating illness titled Not Always on the Level (1).

Moran was born in 1925, the son of a Yorkshire general practitioner. In 1950, he obtained his medical degree at the Middlesex Hospital Medical School in London, United Kingdom, and shortly after, began research in the Department of Physiology at the same institution. He used the new technique of electromyography, together with pressure and volume measurements, to provide the first comprehensive description of the mechanical events during breathing and the neural mechanisms that controlled the respiratory muscles. The Respiratory Muscles and the Mechanics of Breathing (2) remains the seminal work on these topics. In it, he developed a diagram by which the work and power of breathing could be partitioned between that performed on the lung and that performed on the chest wall. This remains the standard tool used today to measure intrinsic positive end-expiratory pressure and to partition respiratory work between the ventilator and the patient in intensive care units.

I was lucky enough to work with Moran in the 1960s, during his heyday in research at the Hammersmith Hospital. It would be hard to overestimate the number of trainees and fellows who directly benefited from Moran's teaching and direction; for all of them, the experience had a profound and lasting effect. He taught us that experimental design based on understanding of basic principles is important; that simple measurements that were logically based were better than the most sophisticated technology; that there was a proper way to keep records; and that a study was not complete until it was published.

He arrived at the Hammersmith Hospital soon after two of his papers had appeared in The Lancet (the first presented the underlying physiological problems in respiratory failure due to chronic lung disease [3] and the second showed how such patients might be logically treated [4]). Up to that time, the approach had been to administer intermittent oxygen therapy, which was supposed to remedy lack of oxygen while avoiding a worsening situation due to carbon dioxide retention. Moran characterized this approach as being similar to bringing a drowning man to the surface and then pushing him back under to a greater and greater depth. His approach was to administer a mixture of air with oxygen to provide modest oxygen enrichment and, thereby, prevent carbon dioxide retention. He devised a mask in which oxygen was delivered through a narrow jet; this led to a Venturi effect, which drew in room air to dilute the oxygen. The effect depended on the bore of the jet - the narrower, the greater the dilution. A series of

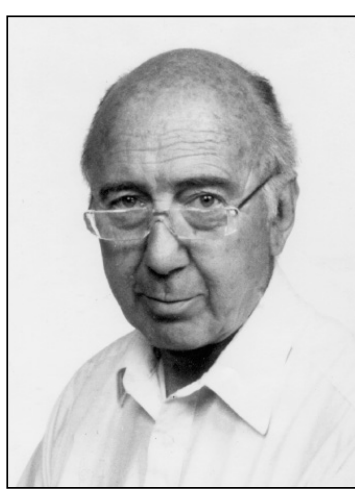

EJ Moran Campbell (1925-2004) jets were engineered in brass, and eventually, three were manufactured in plastic to provide oxygen concentrations of $24.5 \%, 27 \%$ and $35 \%$. Moran had shown that this strategy always improved oxygenation and he argued that this meant one did not need to measure oxygen; what did need measuring was the blood carbon dioxide pressure. On his early ward rounds, we were all clued-up on how to administer oxygen, but the measurement of carbon dioxide was beyond us, and in any case, time consuming and not very accurate. Moran demonstrated a method that involved rebreathing in and out of a small anesthesia bag to obtain equilibration between the gas in the bag and the blood flowing through the lungs; the gas could then be analyzed at the bedside by a simple chemical technique. We could measure carbon dioxide pressure accurately in less than 10 min without leaving the patient; it was a fantastic advance. Woe betide the resident who phoned Moran about a patient without first measuring $\mathrm{PCO}_{2}$. There was an apocryphal story that on one occasion, 10-year-old Fiona answered the phone to tell the resident "measure the $\mathrm{PCO}_{2}$ and call Daddy after".

We always met once a week to review progress on various projects; this was not just some sterile supervision session, but a time when new ideas were floated. The question "What happens if you go on rebreathing after the equilibration?" led to a novel way of measuring the control of breathing, which has remained the gold standard since then, partly because it fulfilled the control engineer's requirement for 'open loop' conditions. This project was taken on by David Read from Sydney and it has since been known as the 'Read method' - a small indication of Moran's generosity when it came to attribution of a piece of research. "How fast does the carbon dioxide pressure increase as you rebreathe?" led to a new understanding of how $\mathrm{CO}_{2}$ is stored in the body. "What can we learn if we rebreathe during exercise?" led to an innovative approach to assess heart, 
lung and metabolic responses for exercise testing. Moran guided all these projects through to their presentation at meetings as papers or posters, and to publications. Presentations were preceded by several rehearsals, which were always character forming, but we soon learnt that Moran always rehearsed his own talks more than any of us and took criticism in the same spirit. Drafts of papers were invariably returned covered in red ink and full of three and four letter words, of which "ugh" was the most common.

Moran kept his most combative and articulate performances to his presentations at scientific meetings. In 1967, he was invited to give the J Burns Amberson Lecture of the American Thoracic Society. He was the youngest scientist to give the lecture and it was, in every way, a triumph, full of humility and arrogance, revealing equations, insightful diagrams, classical allusions and phrases that have remained in the memory ever since ("some patients can't breathe but a lot won't breathe", "in some hospitals, to get the full attention of a nurse, you have first to get your throat cut", "intensive care doctors would do much better if they were less intense and a lot more careful"). The text of this lecture still deserves to be on every respirologist's desk.

Some of the concepts and diagrams he advanced were hard for most of us - the concept of length-tension inappropriateness and the accompanying circuit diagram that he developed with Jack Howell to explain breathlessness, thankfully became simplified over the years as he worked with Kieran Killian to measure its intensity under a large number of experimental designs.

He was the Editor-in-Chief of Clinical Science in the early 1960s and the senior author of Clinical Physiology (5), the standard undergraduate textbook that has remained current through many editions.

In 1968, Dr Campbell crossed the Atlantic to become the founding chair of medicine at the new medical school at McMaster University. Probably his greatest legacy to McMaster was the recruitment of clinical scientists from across the world to the Department of Medicine, but he also attracted many senior recruits to other departments in the faculty.
Moran was an outstanding educator, being especially effective in Socratic teaching. He is best remembered for his teaching at the postgraduate level and at the weekly Grand Rounds of the Department of Medicine, where he sparked articulate debate with a mixture of wit and logic. He was deeply interested in undergraduate education and provided much guidance as the curriculum of the McMaster programme was developed. Education, not training, was his credo.

Over the years, as his mood swings became more frequent, the highs higher and the lows deeper, we struggled to help. Dealing with his highs involved an escalating series of strategies, from supportive humouring to preventing public performances, and finally, to pleas for help to his psychiatrist. Dealing with the lows was, if anything, more frustrating, for his black moods were impossible to break through. These situations were poignantly described in Not Always on the Level (1). Reading this book, one realizes that all these features of his illness were analyzed with his customary insight and humour.

Outside of medicine, his interests were wide and varied. He loved literature and music, sports and cottage vacations. A lifelong cyclist, he lobbied hard and successfully for cycle paths in and around Hamilton. He could not have achieved or accomplished what he did without the dedicated and loving support of Diana, his wife of 49 years, and their four children, Fiona, Susie, Robert and Jessica.

His colleagues have established a fund in his honour to provide for The Moran Campbell Senior International Fellowship in Medicine (McMaster University Downtown Centre, Room 125, 1280 Main Street West, Hamilton, Ontario L8S 4L8).

\section{REFERENCES}

1. Campbell EJM. Not Always on the Level. London: The Memoir Club, 1988.

2. Campbell EJM. The Respiratory Muscles and the Mechanics of Breathing. London: Lloyd-Luke, 1958.

3. Campbell EJM. Respiratory failure: The relation between oxygen concentration of inspired air and arterial blood. Lancet 1960;2:10-1.

4. Campbell EJM. A method of controlled oxygen administration which reduces the risk of carbon-dioxide retention. Lancet 1960;2:12-4.

5. Campbell EJM, Dickinson CJ, Slater JDH, Edwords CRW, Sikora K. Clinical Physiology. Oxford: Blackwell Scientific Publications, 1984. 


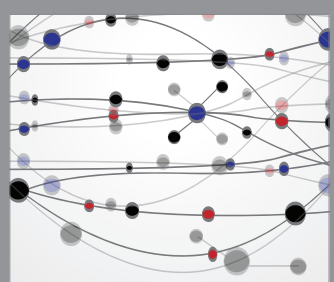

The Scientific World Journal
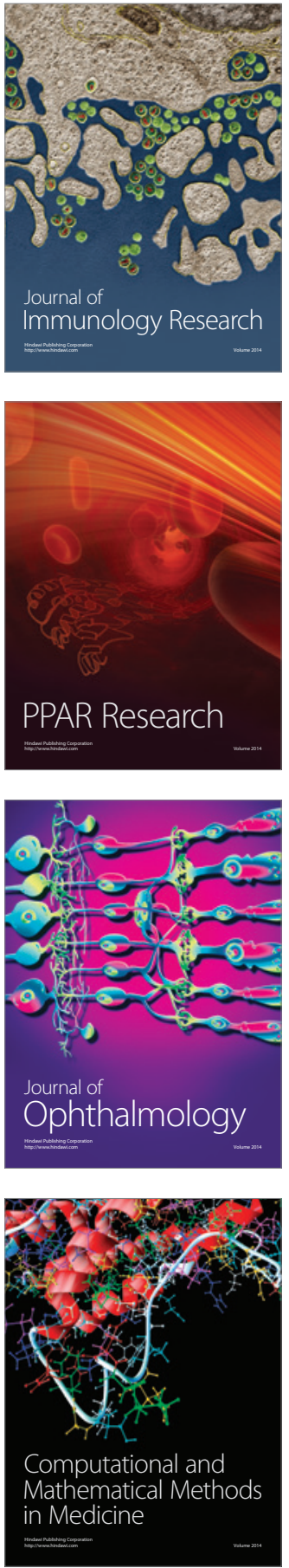

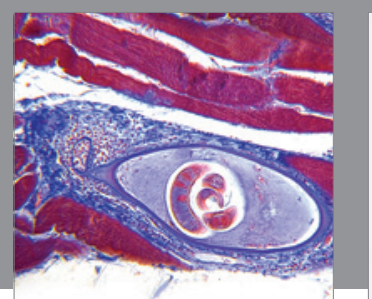

Gastroenterology Research and Practice

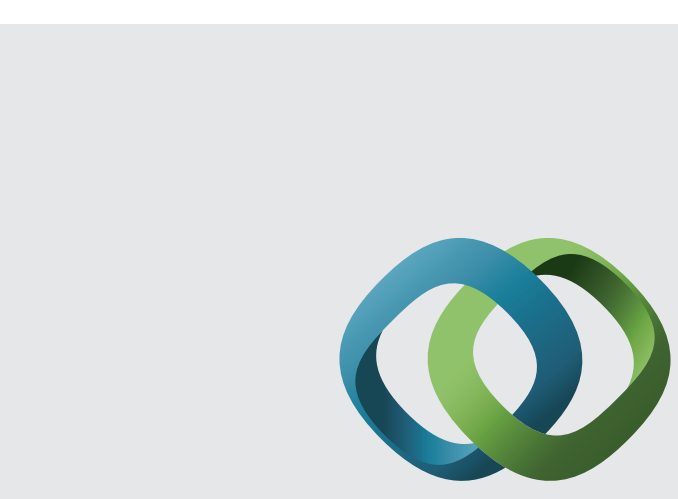

\section{Hindawi}

Submit your manuscripts at

http://www.hindawi.com
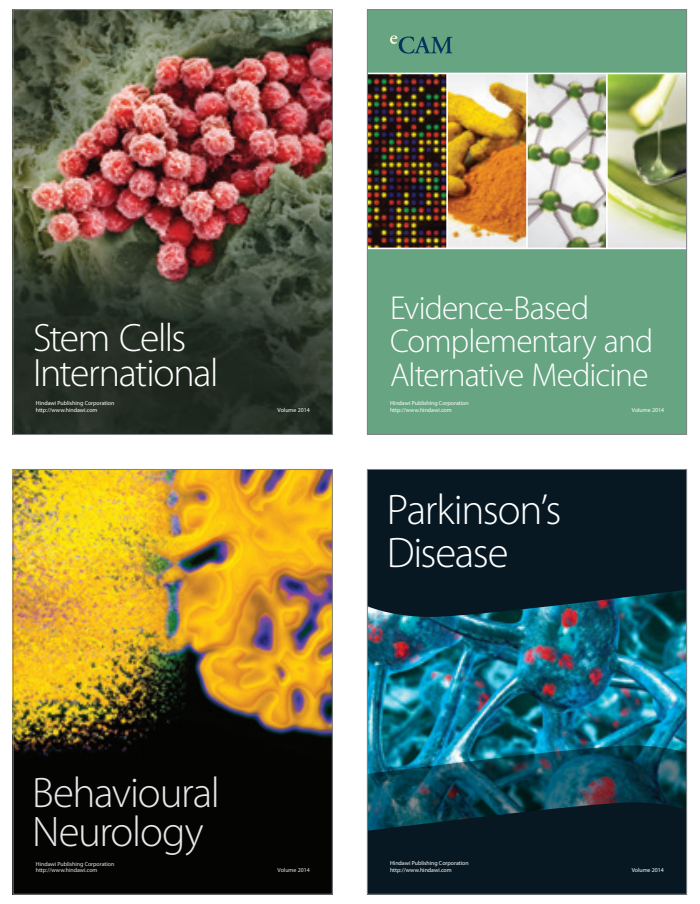
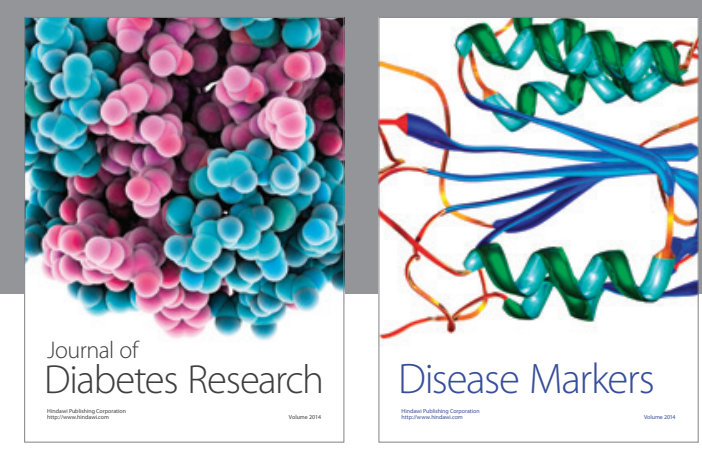

Disease Markers
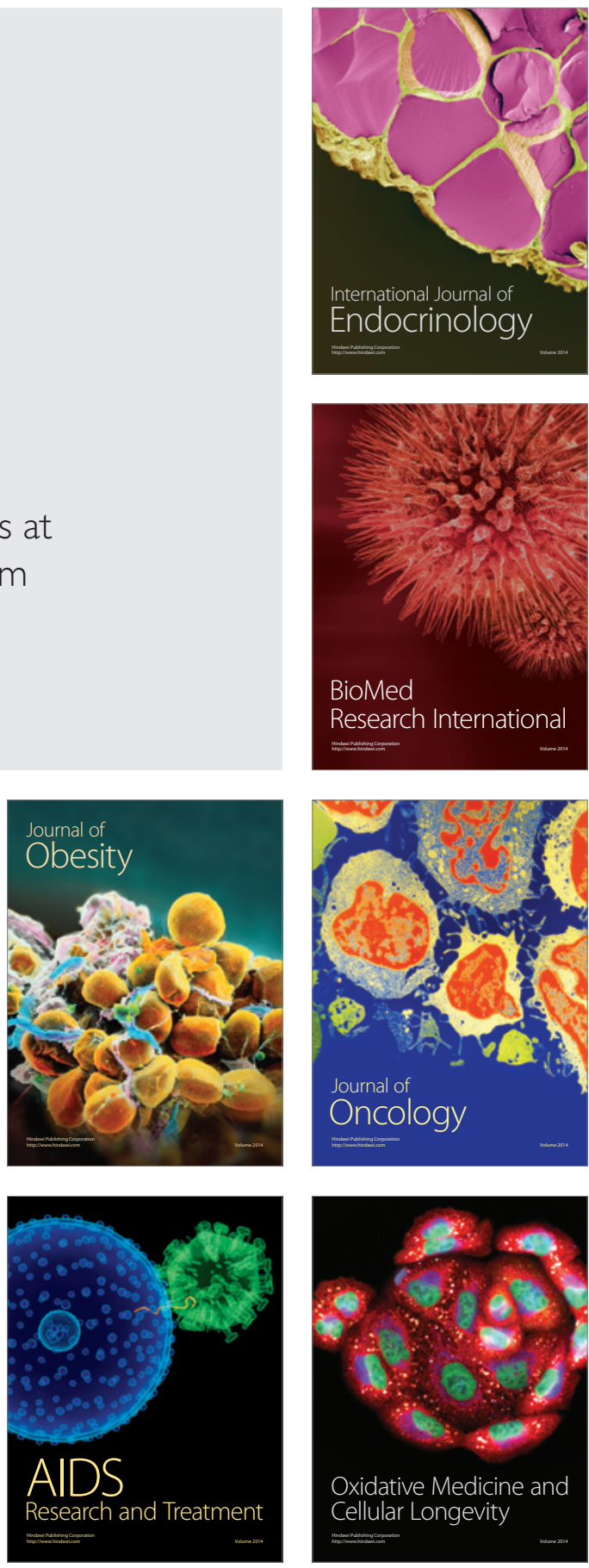